As to treatment, quinine, digitalis, antipyrin, etc., seem to be worse than useless, but tepid or cold washing, whenever the temperature reaches $102^{\circ}$, is certainly of very great use; ice on the head, milk diet, and a small quantity of stimulants towards the end of the illness have been prescribed in my case. I also gave acetate of ammonia, with the view of increasing elimination by the kidneys.

\section{ON ACUTE ANTEFLEXION OF THE UTERUS IN THE LATER MONTHS OF PREGNANCY.}

By JAMES BRAlTHWAITE, M.D.LOND.,

Obstetric Physician to the Leeds General In firmary.

A CASE of pregnancy was sent to the Leeds Infirmary in September, 1892, with a letter from two medical men of experience, saying that they believed the case to be one of extrauterine gestation.

The patient was aged 34, and had had five children, the last two years ago. In April, 1892. the patient believed herself to be again pregnant In July she began to bleed a little every day but in small amount, and this hamorrhage continued up to the time of her admission in September. There was a large rounded central abdominal tumour reaching half a finger's breadth above the umbilicus, and occupying the greate portion of the abdominal cavity below. Whether this was the womb or not it clearly contained a living child, for its movements could be felt by the hand. Vaginal examination found a rounded swelling anteriorly and the uterus apparently lying behind it: and with no continuity with it so far as the nnger alone could ascertain. The finger, pressed up between the tumour and the cervix, did not arrive at any point of union. The uterus also seemed to be movable independently of the tumour' to the moderate degree which its cramped position behind it admitted, for it was pressed against the sa'rum. This, as it will be seen, turned out to be a mistake, but at the time it gave me this impression. The cervix was very dilatable, and 1 passed an index finger up, and at a height of about 2 inches leached the top of a very elongated cervix. The finger could then be turned forward into the cavity of the uterus, and the foetal head, covered by the membranes, was felt. Labour came on the same dav, and was concluded satisiactorily.

I certainly thought on first examination that the child was not in the uterine cavity. In the year 1888 I was associated with Mr. E. O. Croft. of Leeds, in a similar case.

Precisely the same condition was found as in the ease already described, and much doubt existed whether the child was really in the womb or not. The cervix, or the uterus, lay directly behind the tumour and parallel to it, and no continuity, or but a doubtful one, between them could be detected. I dilated the cervix sufficiently to admit of the passage of the finger, which at the height of fully 2 inches reached a ledge anteriorly, over which it could be passed somewhat downwards and forwards into the uterine cavity. The ledge was formed by the angle between the cervix and body, and it was necessarily pressed downwards to admit of access to the uterine cavity. I ruptured the membranes, and the labour was completed the same evening or next morning by my friend, but it was difficult.

At the beginning of November, 1892, I admitted another case in to the rvard, precisely like the other cases related. It should be noticed that in these cases there was anteflexion only, without more version than enough to draw the cervix upwards a little. Secondly, that the cervix was somewhat elongated and pressed between the body of the uterus and the sacrum. It was not carried up almost out of reach as.in the ordinary anteversion with pendulous belly, but it was a little elevated. Thirdly, all the cases were primiparæ, and, as might be expected, in none of them was there what is known as pendulous belly with separation with the recti muscles. Indeed, the two conditions-acute flexion and pendulous belly - are inconsistent with each other, for it is the absence of yielding in the abdominal walls which favours the flexion.

Although there are many references to anteversion with pendulous belly, there are as far as I can discover. on record only two cases of the condition which forms the subject of this paper. Matthews Duncan, in his Tiseceses of Women (1886, p. 397), says that in advanced pregnancy we have two kinds of anteversion; one, common pendulous belly, the other extremely rare; he adds, "I have seen only one case of it in a primipara." In this case the uterus was anteflexed, and could not be replaced as in common pendulous belly. . It was, in Duncan's opinion, not displaced secondarily, but grew into this peculiar shape and position.

A second reference to it is in the American Journal of $\mathrm{Ob}$ stetrics (February, 1890, p. 156) in which a case is recorded as one of "dextro-torsion of the pregnant uterus simulating extrauterine pregnancy." This case is precisely like those I have related $f x c e p t$ that the body of the uterus fell to the right side instead of directly anteriorly. The writer of this paper is Dr. W. H. Wenning, of Cincinnati. The case ro exactly simulated extrauterine gestation that after. numerous consultations and examinations Dr. Wenning and his friends proceeded to abdominal section.

On opening the body Dr. Wenning says, to use his own words, "general surprise and consternation seized us all," for nothing was found but the pregnant uterus bent like a retort.

Dr. Wenning made a complete search into the German literature of the subject and he states that Küstner ${ }^{1}$ relates a similar case to his, except that the patient was in an earlier stage of pregnancy. Barnes, in his Diseases of Women (1873, pp. 671.672) observes: "In some rare cases of early pregnancy the fundus has been locked behind the symphysis pubis in complete anteversion, forming a counterpart to the retro. version of the gravid uterus."

This anteflexion of the early months has, however, no direct connection with the present subject, which is the resemblance such cases in the later months have to extrauterine gestation and the difficulty of diagnosis. It is probable that this condition is more common than has been supposed, and its similarity to extrauterine gestation must be remembered.

In every case, however, of advanced or full term abdominal ectopic gestation which I have seen-and I have now operated upon six-the uterus lay in front of the sac containing the child, not behind it. 'This is a most important point in the diagnosis, but there can be no absolute certainty until the finger is passed up the dilated cervix.

\section{TOTAL EXTIRPATION OF THE UTERUS.}

By MACPHERSON LAWRIE, M.D.,

Physician to the Sanatorium for Discases of Women, Weymoutfi.

Mrs. F., aged 66, a widow, consulted me during November; 1892 , on account of pain in the region of the uterus, and a vaginal discharge. These symptoms had been in existence for about one year. The discharge was at first muco-purulent, but for three months had assumed a hæmorrhagic character, and the pain had become very severe. The periods ceased at the age of 50 .

On November 20th the uterus was dilated, and an indurated, nodular mass found to occupy the upper part of the uterine cavity. This was thoroughly scraped away with the curette.

This operation was followed by great relief, but in three months the symptoms returned. The uterus was again dilated, and the growth, which had attained greater size, was again thoroughly curetted. For a second time the patient's condition was much improved, but in six weeks the old symptoms began to return. A third time the uterus was dilated. The growth was found to have developed more rapidly. With a strong, sharp curette the growth and underlying tissues were completely scooped out, till almost the whole thickness of the uterus at that part had been removed.

Severe constitutional disturbance took place after this operation, but the results seemed all that could be desired for some four or five months, when she wrote to say that the pain had recurred in a most severe form, and was accompanied by considerable hæmorrhage. It was now quite useless to propose any further palliative measures, and she consented to face the risk of complete removal of the uterus.

The operation took place on October 25th, 1893, The patient had never had any children. and the vagina was so. narrow that it was necessaly to divide the perineum and recto-vaginal septum down to the bowel, and afterwards to stretch the enlarged vagina by means of retractors.

The uterus was somewhat higher than usual in the pelvie cavity. The os could be distinguished towards the upper extremity of the vagina. After dragging down the uterus by means of a pair of single-toothed forcens attached to the posterior lip. it became possible to make out the cervix invested by the bladder in front. A firm hold of the posterior part of the cervix was obtained by means of a strong vulsellum, the uterus pulled down as far as possible, and the vulsellum given to my friend. Dr. Smyth, who was assisting in the operation, to hold. The vaginal mucous membrane was

\footnotetext{
i Handbuch der Geburtshillfe, Band 11, r. 54i, 1889
} 